\title{
ARTICLE OPEN \\ A mechanistic investigation of corrosion-driven organic coating failure on magnesium and its alloys
}

\author{
Geraint Williams (iD ${ }^{1 *}$, Christos Kousis ${ }^{1}$, Neil McMurray ${ }^{1}$ and Patrick Keil (D) $^{2}$
}

The failure mechanism of model organic coatings from Mg alloy surfaces is characterised by a combination in-situ scanning Kelvin probe analysis and time lapse photography. Initiation of underfilm corrosion by application of group I chloride salts to a penetrative coating defect produces an apparent cathodic-driven coating delamination, where the disbondment distance increases linearly with time at high relative humidity, although filiform corrosion (FFC) is also observed in the vicinity of the defect. The disbondment process occurs both in the presence and absence of oxygen, indicating that hydrogen evolution comprises the predominant underfilm cathodic reaction. Post-corrosion elemental analysis of the delaminated region shows an abundance of group I cation, but no chloride. When magnesium chloride or $\mathrm{HCl}$ are used to initiate corrosion, then only FFC is produced. The mechanism is discussed in terms of net anodic dissolution at the defect coupled with underfilm cathodic hydrogen evolution, producing organic coating disbondment under conditions where cations are able to transport ionic current within a zone of increased $\mathrm{pH}$.

npj Materials Degradation (2019)3:41; https://doi.org/10.1038/s41529-019-0103-4

\section{INTRODUCTION}

There is significant current interest in developing protective coatings for magnesium $(\mathrm{Mg})$ alloys to overcome problems of poor corrosion resistance which presently limit their widespread use. The vast majority of publications dealing with this topic relate to inorganic barrier coatings and pre-treatments ${ }^{1,2}$ and relatively few scientific studies of corrosion protection by organic coatings are available. A recent review identified types of protective organic coating technologies which could be prove effective when applied to $\mathrm{Mg}$ based surfaces and highlighted methodologies which could potentially be used to quantify corrosion protection efficiency. ${ }^{3}$ Previously published works have evaluated the ability of electrophoretically deposited organic coatings (Ecoat) to protect of $\mathrm{Mg}$ alloys in accelerated corrosion tests. ${ }^{4,5}$ It was proposed that corrosive electrolyte penetration and resultant formation of corrosion products at the coating-metal interface, such as magnesium hydroxide and hydrogen gas, caused delamination by physically forcing the coating from the metal surface. ${ }^{4}$ A separate investigation showed that the presence of soluble inorganic salts at the metal-coating interface of polyester coated AZ91 Mg alloy caused osmotic blistering and subsequent corrosion-induced damage. ${ }^{6}$ However, despite these prior investigations, the precise mechanisms of organic coating failure remain unclear and there is an urgent need to better understand the processes which lead to corrosion-driven coating disbondment from Mg based surfaces.

In a previous study, employing model poly-vinyl butyral (PVB) coating applied to commercially pure $\mathrm{Mg}$ under atmospheric corrosion conditions, we demonstrated that chloride induced damage in the vicinity of a penetrative coating defect took the form of filiform corrosion (FFC). ${ }^{7}$ The rate of filament propagation was shown to be insensitive to the presence of oxygen, and that chloride ions were conserved at the corrosion front, indicating an anodic undermining disbondment mechanism. This present work expands on this previous investigation by employing a technologically important $\mathrm{Zn}-\mathrm{Zr} / \mathrm{Nd}$ based magnesium alloy (commercially available Electron ${ }^{\mathrm{TM}} 717$ (E717), also known by other alloy designations as ZE10 or ZEK100). The promising mechanical properties of this particular alloy for certain automotive applications ${ }^{8,9}$ has led to a significant present interest in understanding its corrosion behaviour, both in the presence ${ }^{5}$ and absence $^{10}$ of an organic protective coating. Using model PVB coatings applied to E717 substrates, underfilm corrosion was initiated by applying a range of different chloride based containing salts to a penetrative coating defect, including $\mathrm{NaCl}, \mathrm{LiCl}, \mathrm{KCl}$, $\mathrm{CsCl}, \mathrm{MgCl}_{2}$, and $\mathrm{HCl}$. Certain key experiments, notably when $\mathrm{NaCl}$ (aq) was used to initiate underfilm corrosion, were repeated for other commonly used $\mathrm{Mg}$ alloys, such as AZ31 and AZ91, along with a pure $\mathrm{Mg}$ sample to assess whether observations made using E717 were either unique to this type of alloy or generic to other types of $\mathrm{Mg}$ based surfaces. Coating failure rates were evaluated by a combination of time-lapse photography and in-situ scanning Kelvin potentiometry while holding the specimens at a constant humidity of $93 \%$ at room temperature. The first aim of this work was to determine the role of the initiating chloride salt in the type of underfilm corrosion damage observed. Upon identifying a different type of coating failure in the presence of group I chloride salts, a further aim became comprised efforts to characterise controlling factors in organic coating delamination in order to elucidate the prevailing disbondment mechanism.

\section{RESULTS}

Delamination of model polymer coated alloy surfaces

Preliminary experiments using PVB coated E717 specimens were designed to assess the difference between underfilm corrosion morphologies produced upon initiation by equivalent concentrations of either $\mathrm{HCl}(\mathrm{aq})$ or $\mathrm{NaCl}(\mathrm{aq})$. Previous investigations involving organic coated aluminium alloy surfaces have shown that the methodology employed here, involving the direct injection of a controlled quantity of aqueous chloride containing solution directly into a fixed length of penetrative coating defect, 

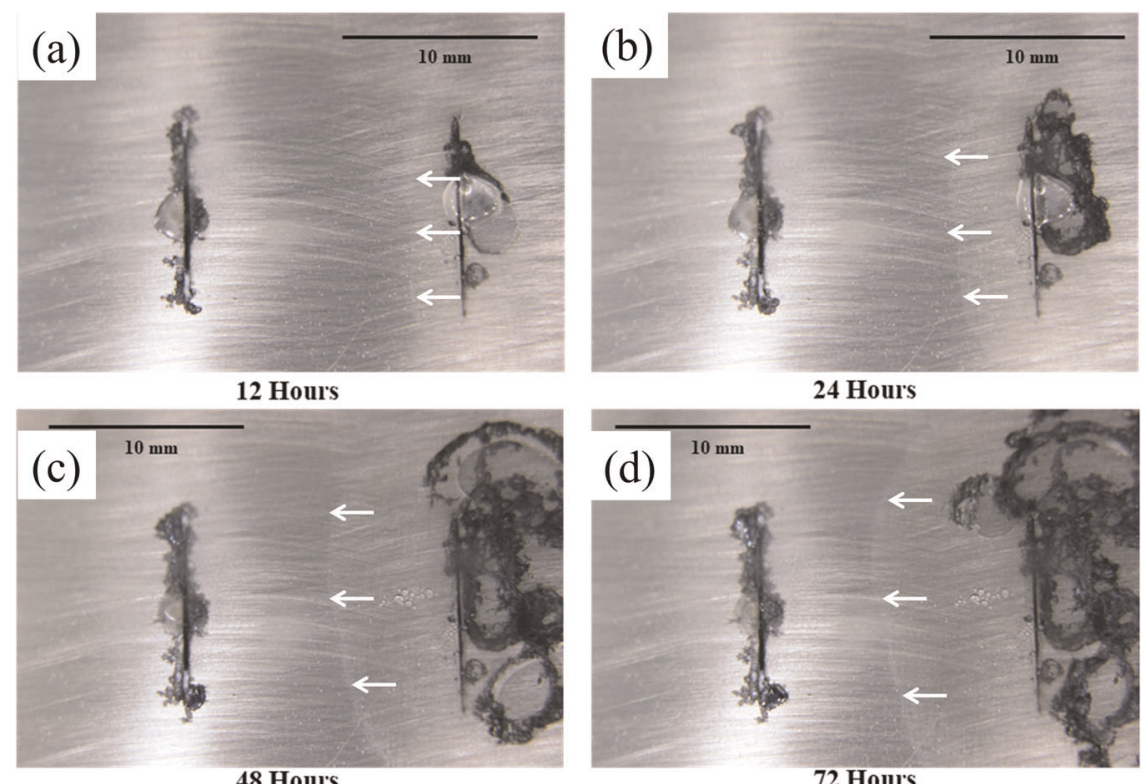

Fig. 1 Photographic images of a PVB coated E717 alloy undergoing corrosion at a constant relative humidity of $95 \%$ after periods of a $12 \mathrm{~h}$, b $24 \mathrm{~h}, \mathbf{c} 48 \mathrm{~h}$, and $\mathbf{d} 72 \mathrm{~h}$ following corrosion initiation by applying $\mathrm{HCl}$ (aq) (left) and $\mathrm{NaCl}$ (aq) (right) to a penetrative coating scribe.

reproducibly generates filiform corrosion in such a way as to facilitate kinetic investigations on underfilm corrosion propagation. ${ }^{11}$ Figure 1 shows a series of images of a PVB coated E717 specimen, comprising two separate scribed coating defects, held in humid air for increasing time periods following initiation of corrosion. Underfilm corrosion was initiated using $\mathrm{HCl}$ (aq) on the left hand side defect, while aqueous $\mathrm{NaCl}$ was applied to the defect on the right. A network of black tracks is observed in the vicinity of the left hand side defect region, which appears to grow slowly with holding time, extending to a maximum distance of $\mathrm{ca}$ $2 \mathrm{~mm}$ either side of the defect over a 3 day holding period. Initiation of underfilm corrosion using $\mathrm{NaCl}$ (right hand side, Fig. 1a-d) also produces dark corrosion product in regions adjacent to the defect, which grow in area with respect to holding time at a significantly more rapidly than is the case for $\mathrm{HCl}$ initiation. However, somewhat surprisingly underfilm corrosion is also characterised by the development of a halo surrounding the defect region, whose leading edge (see arrows on Fig. 1a-d) extends further from the defect with time. Figure $1 d$ shows that the visible halo edge has propagated over a distance of ca 8-9 $\mathrm{mm}$ during the 3 day holding time. Although the leading edge of the halo remains highly visible at all times, the $\mathrm{Mg}$ alloy surface within the halo to the left side of the penetrative defect appears largely uncorroded and free of black corrosion product. No such halo could be observed in the vicinity of the defect region where corrosion was initiated via the application of $\mathrm{HCl}$. Upon removal of the specimen from the humidity chamber, it was confirmed that PVB coating was de-adhered from the Mg alloy surface in the region occupied by the halo, but remained adherent to the surface at a point marked by the leading edge. Repeat experiments carried out using different concentrations of $\mathrm{NaCl}$ (aq) in the $0.1 \mathrm{M}-1 \mathrm{M}$ range also gave similar results, where an apparently uncorroded region surrounding a penetrative defect was affected by organic coating delamination. The same behaviour was also observed for PVB-coated AZ31 and AZ91 alloy surfaces when $\mathrm{NaCl}(\mathrm{aq})$ electrolyte was applied to a scribed coating defect in order to initiate underfilm corrosion.

In order to determine the free corrosion potentials $\left(E_{\text {corr }}\right)$ associated with the underfilm delamination cell apparently set-up in the presence of $\mathrm{NaCl}(\mathrm{aq})$ applied to a coating defect, a separate experiment was carried out by using a Scanning Kelvin probe to map an area of the coated E717 surface. Figure 2 shows a series of SKP-derived greyscale image maps obtained by in-situ scanning a region of the PVB coating surface to the right hand side of the defect as indicated by the dashed rectangle on the photographic image of the post-corrosion surface (see Fig. 2d). Average $E_{\text {corr }}$ values in the -1.0 to $-1.1 \mathrm{~V}$ (vs SHE) range are measured for intact (un-corroded) surface to the far left of the maps, consistent with the alloy surface being in a passive state. The region adjacent to the defect, affected by the progress of underfilm corrosion, is shown as an expanding area of significantly lower $E_{\text {corr }}$ in the range -1.2 to $-1.3 \mathrm{~V}$ (vs SHE). The percentage area occupied by the zone of more negative potential progressively increases with holding time and within $40 \mathrm{~h}$ of initiation, has propagated over the majority of the scanned area. De-adhesion of the model organic coating within the zone of depressed $\mathrm{E}_{\text {corr }}$ was confirmed at the end of the experiment by carefully peeling away the PVB coating from the substrate using tweezers. It was observed that the halo leading edge marked the boundary between a physically deadhered region and one where the coating remained fully adherent to the $\mathrm{Mg}$ alloy surface.

The time-dependent evolution of $\mathrm{E}_{\text {corr }}$ distributions associated with the development of underfilm corrosion are perhaps more clearly seen in Fig. 3, which shows profiles of $E_{\text {corr versus distance }}$ from the penetrative defect, obtained at various holding times following initiation. The profiles were recorded within the region indicated by the white dashed arrow in Fig. $2 \mathrm{~b}$. It may be seen that the $E_{\text {corr }}$ values measured for the intact (un-corroded) surface $\left(E_{\text {intact }}\right)$ progressively increase with holding time, but appear to stabilise at values of $-0.98 \pm 0.02 \mathrm{~V}$ vs SHE after $20 \mathrm{~h}$. It seems likely that this change in $E_{\text {intact }}$ results from some initial atmospheric corrosion of highly reactive Mg alloy surface, even in the presence of an intact model organic coating, when introduced to the highly humid holding environment. The same behaviour was observed when a bare E717 surface was held over a protracted period in a humid environment, confirming that the rise in $\mathrm{E}_{\text {intact }}$ derives from a change in the alloy surface rather than a change in the chemistry of the polymer coating.

$E_{\text {corr }}$ values near the penetrative defect approach that expected for $\mathrm{Mg}$ actively corroding in the presence of aqueous chloride ions (ca - $1.3 \mathrm{~V}$ Vs SHE), ${ }^{7}$ whilst the leading edge of the zone of underfilm corrosion is marked by the sharp change in $E_{\text {corr }}$ with an 

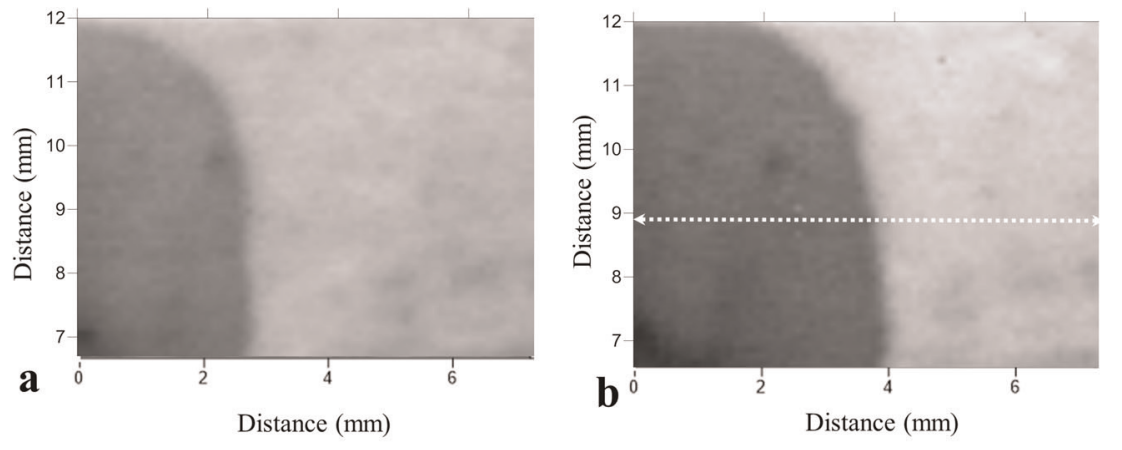

$\mathbf{E}_{\text {corr }} / \mathrm{V}$
vs. SHE
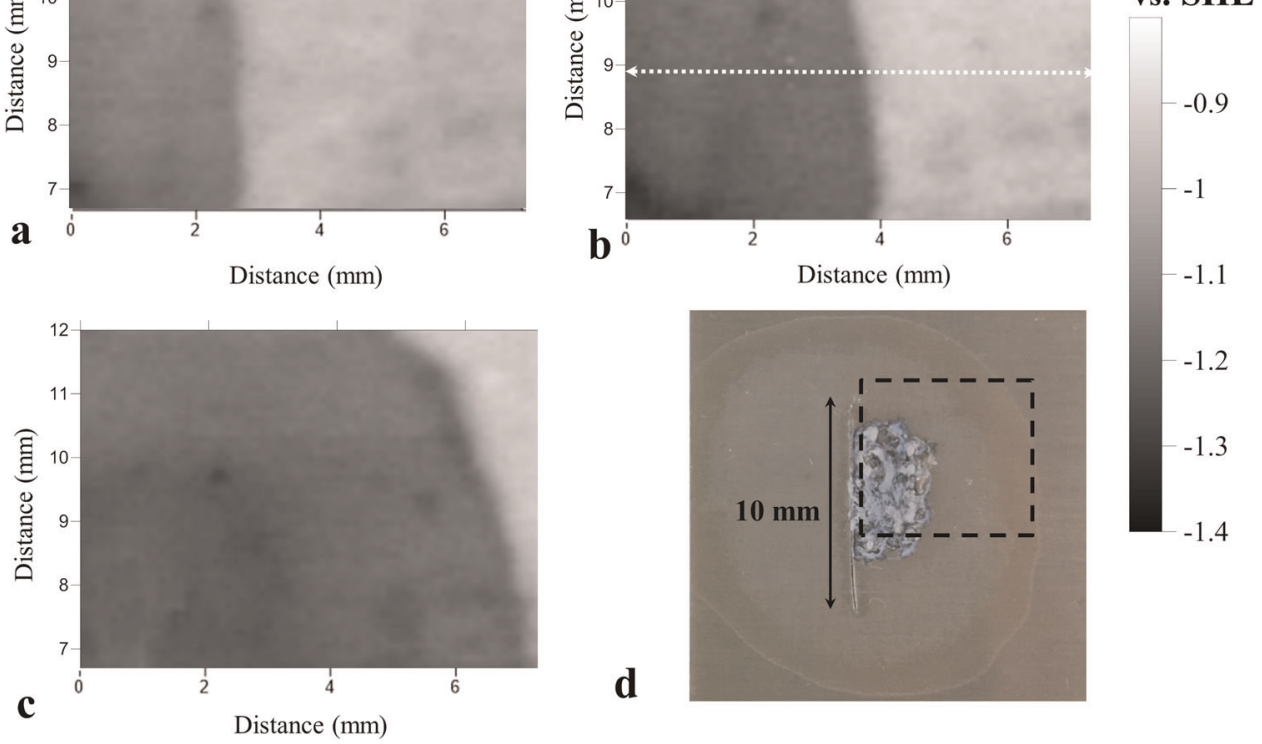

Fig. 2 Greyscale image maps showing $\mathrm{E}_{\text {corr }}$ distributions, measured by in-situ SKP, recorded over a PVB-coated E717 substrate following initiation of corrosion by applying $1 \mu \mathrm{l}$ of $1 \mathrm{M} \mathrm{NaCl}(\mathrm{aq})$ electrolyte to the coating defect region. Time key: a $16 \mathrm{~h}$, b $24 \mathrm{~h}$, and c $40 \mathrm{~h}$, while d shows a photographic image of the sample after $40 \mathrm{~h}$ indicating the region of the coated surface which was scanned.

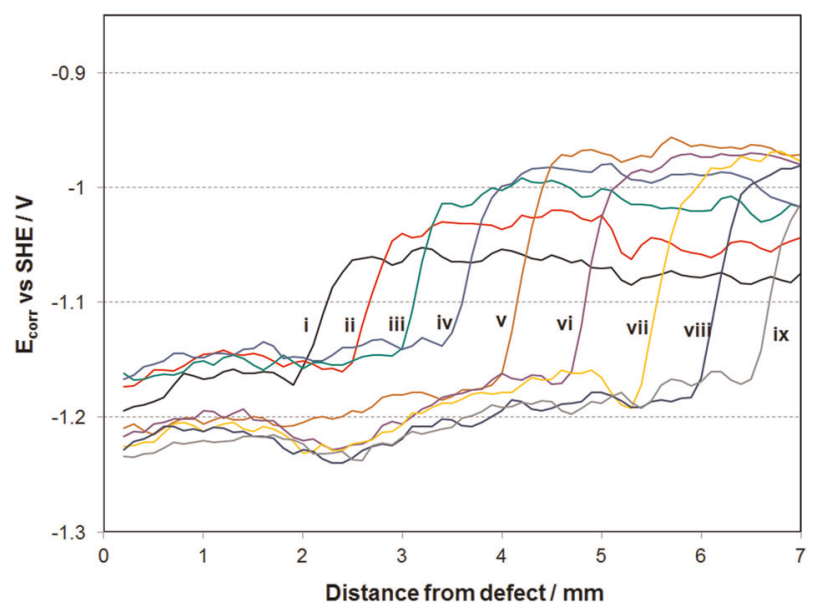

Fig. 3 Profiles of $E_{\text {corr }}$ versus distance from a penetrative coating defect obtained for a PVB-coated E717 sample at various times following initiation of corrosion using $1 \mu \mathrm{l}$ volume of $1 \mathrm{M} \mathrm{NaCl}(\mathrm{aq})$. Time key (i) $6 \mathrm{~h}$, (ii) $10 \mathrm{~h}$ (iii) $14 \mathrm{~h}$ and $4 \mathrm{~h}$ intervals thereafter. The sample was maintained at room temperature and a constant R.H. of $95 \%$ throughout. The arrow on Fig. $2 \mathrm{~b}$ indicates the region of the scanned area where the profiles were recorded.

estimated gradient of ca. $0.4 \mathrm{~V} \mathrm{~mm}^{-1}$. The region which links the leading edge to the defect is characterised by a significantly lower positive gradient of ca. $8 \mathrm{mV} \mathrm{mm}^{-1}$. There appears to be little change in the magnitude the $\mathrm{E}_{\text {corr }}$-distance slopes determined over the corroded surface and at the apparent disbondment front with progressively longer holding times. Therefore, assuming that the underfilm resistivity within these zones remain unchanged over the duration of the experiment, the observation of constant slopes indicates that the ionic current flux coupling the defect to the halo edge remains unaffected by the distance moved by the disbondment front.
At first glance the characteristics of the $E_{c o r r}$ versus distance profiles strongly resemble those reported previously for cathodic organic coating delamination on both iron ${ }^{12-15}$ and zinc ${ }^{16-18}$ substrates, although the absolute values of $E_{\text {corr }}$ are markedly more negative in the present case. Importantly, they do not appear to correlate well with previously published $E_{\text {corr }}$ versus distance profiles obtained for commercially pure, PVB-coated Mg, actively undergoing anodic disbondment via $\mathrm{HCl}$ inoculated filiform-like attack. ${ }^{7}$ In this case the profiles were characterised by the appearance of an $\mathrm{E}_{\text {corr }}$ minimum immediately behind the advancing disbondment front which was coupled to the defect by a zone in which a negative $E_{c o r r}$-distance gradient was observed. It seems evident therefore that the presence of the $\mathrm{Na}^{+}$cations plays a significant role in directing the type of underfilm corrosion observed during chloride-induced atmospheric corrosion of the organic coated Mg alloy surface.

The role of the cation was further investigated by using other group I chloride salts along with magnesium chloride, applied at a concentration of $1 \mathrm{M}\left(0.5 \mathrm{M}\right.$ for $\left.\mathrm{MgCl}_{2}(\mathrm{aq})\right)$ to a penetrative scribe in the model organic coating. Figure $4 \mathrm{a}$, $\mathrm{b}$ shows post-corrosion images of PVB-coated E717 samples taken after exposure to humid air for 3 days following initiation of corrosion using $\mathrm{LiCl}$ and $\mathrm{KCl}$, respectively. In both cases, the appearance of a delaminated halo surrounding the defect is evident as indicated by the black dashed arrows. In the case of a $\mathrm{MgCl}_{2}$ initiated specimen (Fig. 4c), only dark filiform-like attack developed in the vicinity of the defect, where individual filaments were observed to lengthen progressively with time. Inspection of the post-corrosion surface showed that the coating was firmly adherent to the Mg alloy surface in regions close to the defect which were not affected by filiform-like activity.

Also included in Fig. $4 \mathrm{~d}$ is an image of the post-corrosion surface observed when a similar experiment was carried out using PVB-coated AZ91 alloy, in this case using a $1 \mu$ quantity of $1 \mathrm{M}$ $\mathrm{NaCl}(\mathrm{aq})$ to initiate corrosion. Although there appears to be less evidence of dark corrosion product in the immediate vicinity of the penetrative coating defect than in the case of E717 substrates, there remains clear evidence of a disbondment halo extending ca. 

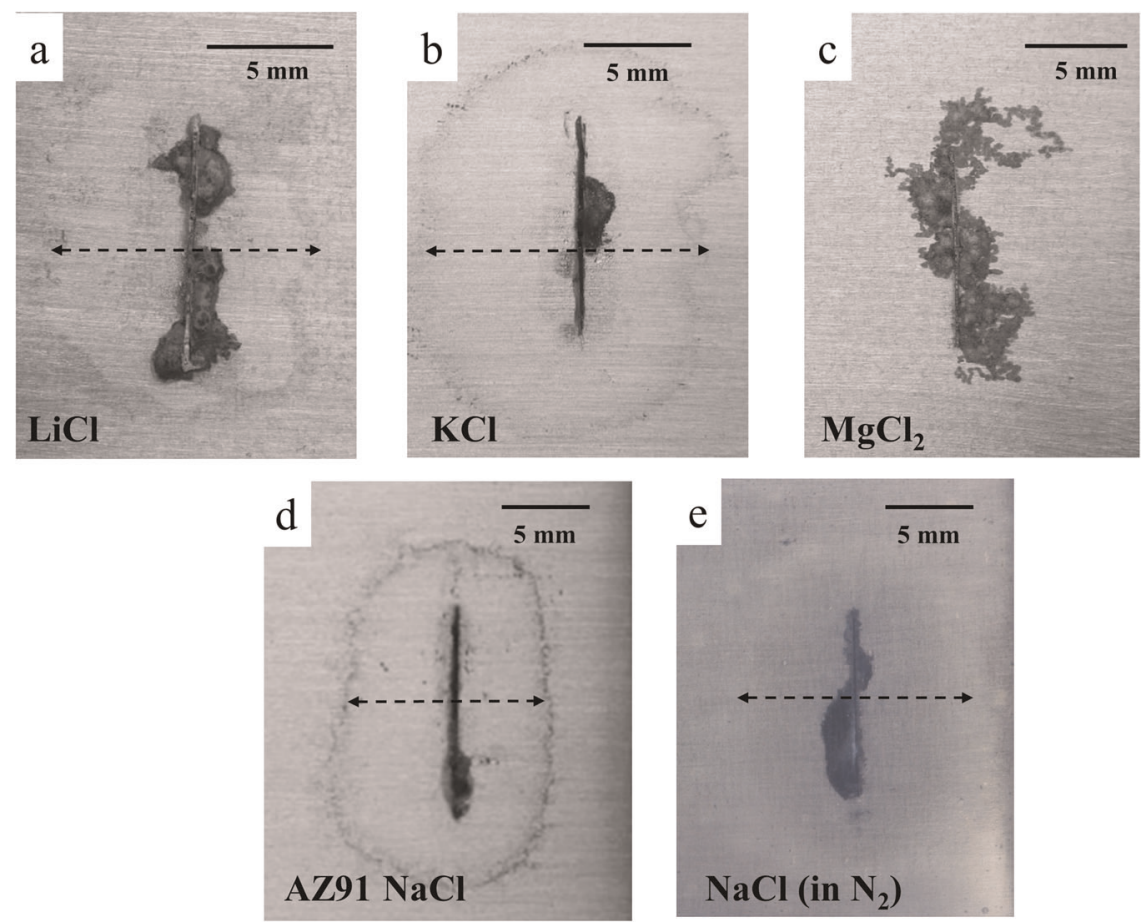

Fig. 4 Photographic images of PVB coated E717 alloy specimens undergoing underfilm corrosion after a $72 \mathrm{~h}$ holding time at $95 \% \mathrm{RH}$, following initiation by applying aqueous $1 \mu \mathrm{l}$ of $1 \mathrm{M} \mathrm{a} \mathrm{LiCl} \mathrm{(aq),} \mathrm{b} \mathrm{KCl} \mathrm{(aq),} \mathrm{and} \mathbf{c ~} \mathrm{MgCl}_{2}(\mathrm{aq})(0.5 \mathrm{M})$. d shows a post-corrosion PVB coated AZ91 alloy surface held in humid air after initiation using $\mathrm{NaCl}(\mathrm{aq})$, while e shows an $\mathrm{E} 717 \mathrm{NaCl}(\mathrm{aq})$ initiated specimen held in $\mathrm{N}_{2}$ at $95 \% \mathrm{RH}$.

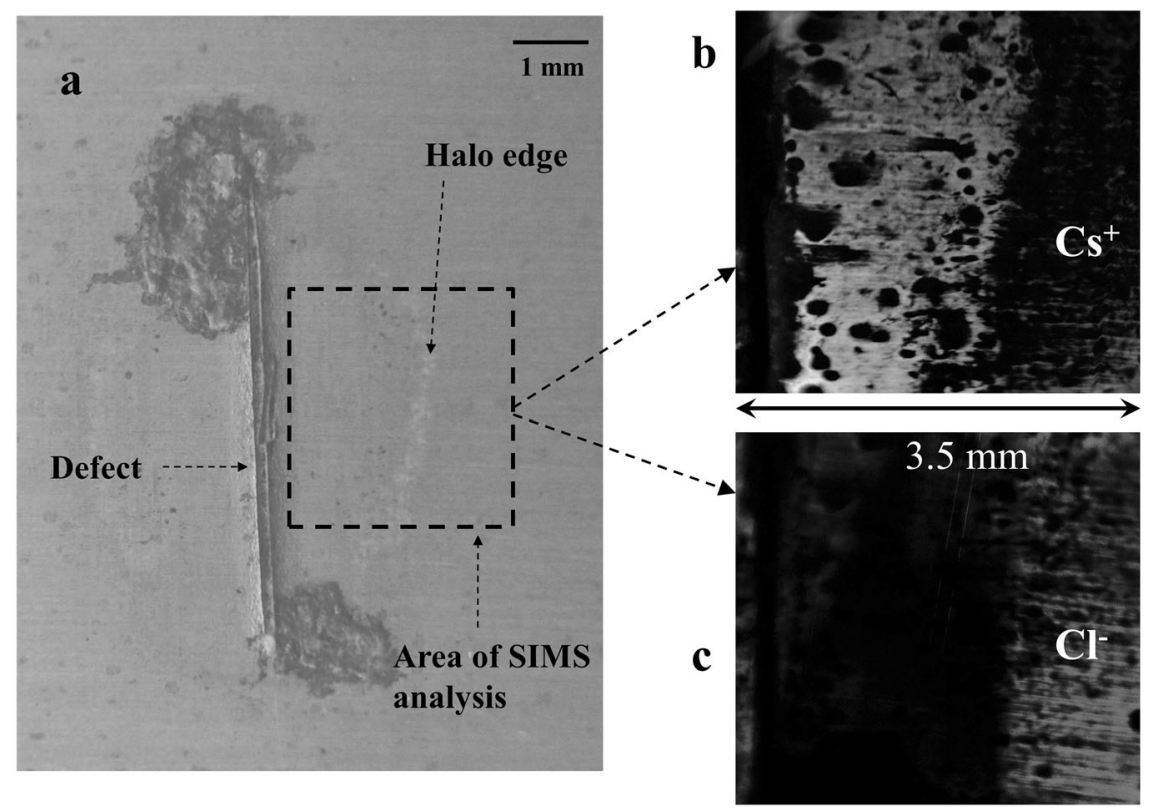

Fig. 5 Post delamination E717 surface imaged using SIMS microscopy $48 \mathrm{~h}$ after initiation of underfilm corrosion using $1 \mu$ l of $1 \mathrm{M}$ CsCl and following the removal of the PVB coating. a shows a photographic image indicating the sample area analysed, along with corresponding b caesium and c chlorine elemental distribution maps.

5-8 $\mathrm{mm}$ from the defect in all directions. Entirely similar results were obtained when the experiment was repeated using an AZ31 substrate, indicating that the phenomenon is not unique to a low alloy rare-earth and zinc containing $\mathrm{Mg}$ alloys such as E717, but also universally affects other technologically important $\mathrm{Mg}$ alloy surfaces.
In a separate experiment, where underfilm corrosion was initiated by applying $1 \mathrm{M} \mathrm{CsCl}(\mathrm{aq})$, the post-corrosion surface was subjected to elemental mapping using secondary ion mass spectrometry after carefully peeling away the model PVB coating. Figure $5 \mathrm{a}$ shows a photographic image of the post-corrosion surface, confirming that the appearance of the disbondment halo 


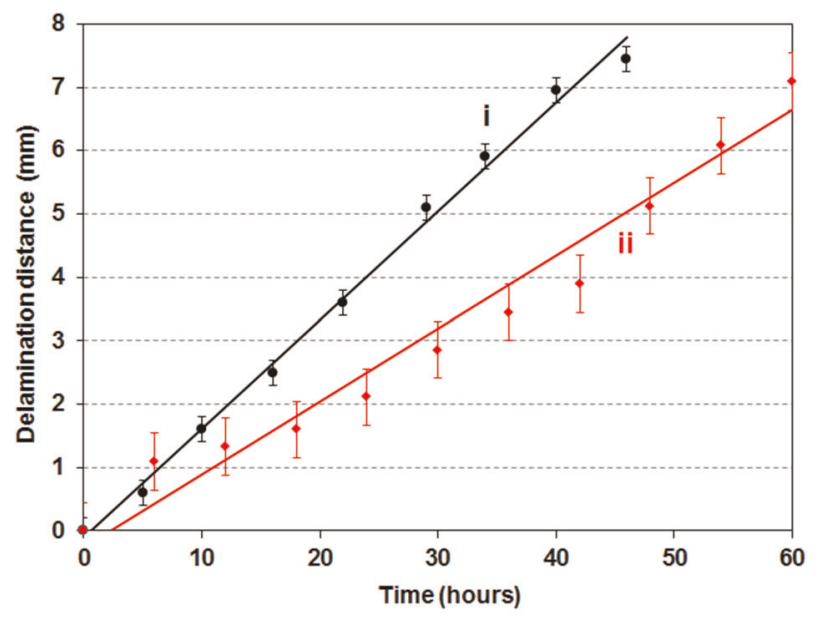

Fig. 6 Plots of disbondment front distance from the coating defect versus time for PVB coated E717 alloy specimens held in (i) air and (ii) nitrogen at $95 \% \mathrm{RH}$. In both cases underfilm corrosion was initiated by applying $1 \mu \mathrm{l}$ of $1 \mathrm{M} \mathrm{NaCl}(\mathrm{aq})$ to a $1 \mathrm{~cm}$ long penetrative coating defect. Average values from 3 repeat experiments are shown and the error bars represent the standard error of the mean.

affects all group I chloride initiated specimens. $\mathrm{Cs}$ and $\mathrm{Cl}$ distribution maps, corresponding with a region of the E717 surface indicated by the dashed rectangle, are shown in Fig. $5 b, c$ respectively as greyscale images. Figure $5 b$ indicates that the entire delaminated halo region is abundant in Cs (shows as light regions), but that no $\mathrm{Cs}$ is detected beyond the leading edge of the disbondment front. Conversely Fig. $5 \mathrm{c}$ confirms that $\mathrm{Cl}$ ions are not co-located with the Cs and are most likely conserved at or near the penetrative defect. The highly surface sensitive nature of the SIMS technique means that common contaminants such as chloride and sodium ions are typically detected on metallic uncorroded surfaces, and accounts for the weak chloride ion signal detected on the right hand side of Fig. $5 c$. The use of $\mathrm{CsCl}$ in preference to $\mathrm{NaCl}$ to initiate underfilm corrosion alleviates problems in elemental imaging caused by the ubiquitous nature of $\mathrm{Na}^{+}$.

Figure 4d also shows a post-corrosion, $\mathrm{NaCl}$-initiated E717 specimen, after holding at high humidity for $48 \mathrm{~h}$, but in the absence of oxygen (i.e. held in a humidified $\mathrm{N}_{2}$ flow). Again the regions immediately adjacent to the defect are affected by dark corrosion product, while an elliptically shaped zone extending ca $7 \mathrm{~mm}$ either side of the defect is also observed. In comparison with a identically initiated specimens held in humid air, the halo observed in the absence of oxygen typically comprised a less well defined leading edge, but a more tarnished interior, indicating a possible difference in atmospheric corrosion behaviour. Nevertheless, close examination of specimens held in humid nitrogen at the conclusion of the experiments confirmed that the halo of PVB coating surrounding the defect was not adherent to the Mg alloy surface. Time-lapse photographic sequences recorded both in humidified air and nitrogen, used in combination with a $1 \mathrm{~cm}$ standard length enabled quantification of the time-dependence of disbondment front advance and the area propagation of the halo surrounding the defect. Typical plots of delaminated distance, measured from the halo leading edge to the penetrative defect, versus holding time obtained for both humidified air and nitrogen environments are given in Fig. 6 . The magnitude of the error bars in plots $\mathrm{i}$ and ii for air and $\mathrm{N}_{2}$ respectively reflects the greater difficulty in identifying the less clearly defined halo edge observed in the absence of oxygen. In both cases, the delamination distance increased linearly with time over the $40 \mathrm{~h}$ duration of the measurement, with slopes of 0.17 and $0.12 \mathrm{~mm} \mathrm{~h}^{-1}$ measured in

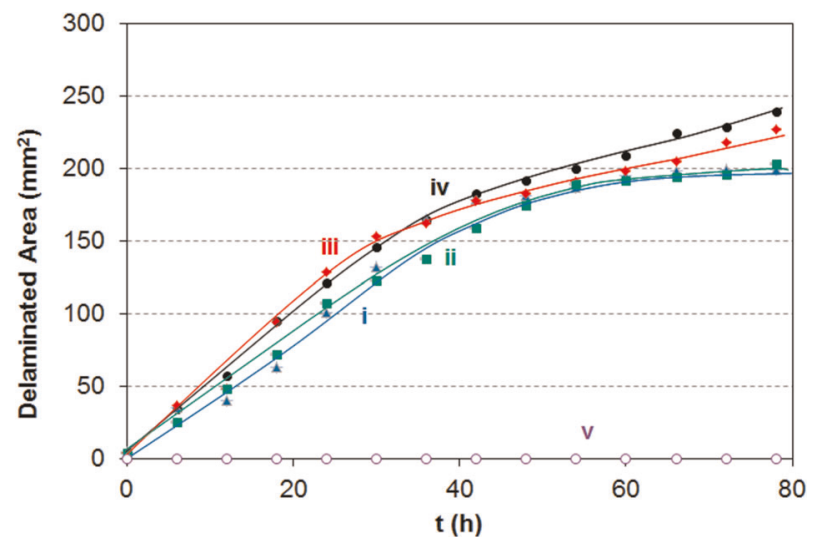

Fig. 7 Plots of delaminated halo area versus time for PVB coated E717 alloy specimens held in air at $95 \% \mathrm{RH}$, where underfilm corrosion was initiated using $1 \mu \mathrm{l}$ of $1 \mathrm{M}$ aqueous solutions of the following: (i) $\mathrm{NaCl}$, (ii) $\mathrm{LiCl}$, (iii) $\mathrm{KCl}$, (iv) $\mathrm{CsCl}$, and (v) $\mathrm{MgCl}_{2}$ (0.5 M in this case).

air and nitrogen respectively. Duplicate experiments confirmed the repeatability of the slower delamination rate measured in the absence of oxygen.

Time-lapse sequences of halo development on group I chlorideinitiated, PVB coated E717 surfaces were also analysed in terms of the time-dependence of coating area delamination. Figure 7 compares the increase in area occupied by the delaminated region surrounding the defect as a function of holding time at 93\% RH in air for corroding specimens initiated with chloride salts of 4 different group I cations, namely $\mathrm{Li}^{+}, \mathrm{Na}^{+}, \mathrm{K}^{+}$, and $\mathrm{Cs}^{+}$. In turn the kinetics of halo area propagation are compared with those observed when an $\mathrm{MgCl}_{2}$ salt was used (see Fig. 7, plot v). Over an initial $30 \mathrm{~h}$ period, delaminated area increases linearly with time for all group I cations and there is little difference in the slopes of the respective slopes, which range from a minimum of $4.1 \mathrm{~mm}^{2} / \mathrm{h}$ (for $\mathrm{Na}^{+}$) to a maximum $5.1 \mathrm{~mm}^{2} / \mathrm{h}$ (determined for $\mathrm{K}^{+}$). In contrast, underfilm corrosion initiated using $\mathrm{MgCl}_{2}$ did not show any delamination caused a visible disbonded halo. It should be noted that the observation that the rate of delamination appears to be independent of the group I cation type differs from the findings of others investigating organic cathodic disbondment on iron. $^{19}$ In this case delamination kinetics are influenced by the diffusion coefficient of the cation and consequently $\mathrm{LiCl}$-induced underfilm corrosion progresses at a significantly lower rate than for equivalent concentrations of $\mathrm{KCl}$ or $\mathrm{CsCl}$. At holding times of $>$ 50 h, Fig. 7 also shows a deviation from linearity for each group I, where the area delamination rate slows significantly, presumably as the finite quantity of cations originally applied to the defect becomes progressively depleted as they become transported into the underfilm region.

\section{DISCUSSION}

The difference in underfilm corrosion behaviour observed when using group I chloride salts compared with either $\mathrm{HCl}$ or $\mathrm{MgCl}_{2}$ is highly evident in Figs. 1, 4, 5. Delamination halos are produced whenever group I cations are present in the initiating electrolyte, but in their absence only filiform-like corrosion is produced. The divergence may be explained on the basis of the solubility of the group I hydroxides of the various cations. While all group I hydroxides are highly water soluble, magnesium hydroxide is only sparingly soluble. In order to establish a delamination cell comprising anodic $\mathrm{Mg}$ dissolution (according to Eq. 1) located on exposed metal at a coating defect coupled with an adjacent underfilm cathode, then ionic current must flow between both 


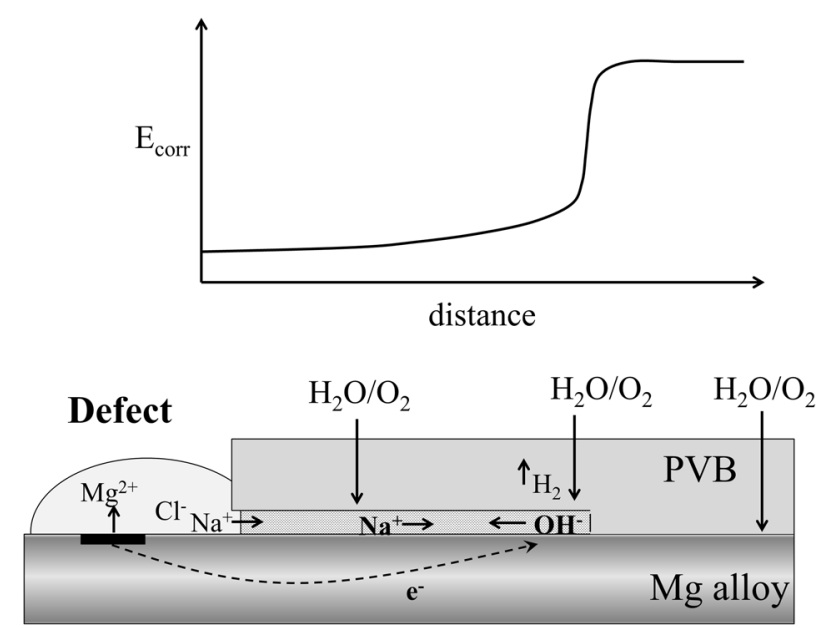

Fig. 8 Schematic diagram showing localisation of the underfilm corrosion cell along with correlation to SKP-derived $\mathrm{E}_{\text {corr }}$ versus distance profile.

sites as shown schematically in Fig. 8. Under the atmospheric corrosion conditions employed in this study (air at 93\% RH), both cathodic oxygen reduction and hydrogen evolution via reactions (2) and (3) respectively are possible.

$$
\begin{aligned}
& \mathrm{Mg} \rightarrow \mathrm{Mg}^{2+}+2 \mathrm{e}^{-} \\
& \mathrm{O}_{2}+2 \mathrm{H}_{2} \mathrm{O}+4 \mathrm{e}^{-} \rightarrow 4 \mathrm{OH}^{-} \\
& 2 \mathrm{H}_{2} \mathrm{O}+2 \mathrm{e}^{-} \rightarrow \mathrm{H}_{2}+2 \mathrm{OH}^{-}
\end{aligned}
$$

However, regardless of the reduction reaction which predominates, the main product of the cathodic process will be hydroxide ions as indicated by both Eqs. (2) and (3). Therefore, to sustain the underfilm corrosion cell, cations must be transported to a local cathode within a zone where a counter current of hydroxide ions will be encountered. It should be noted that underfilm cathodic activity may not be limited to the location of the disbondment front, but may also persist within the remainder of the halo region where coating disbondment has occurred. However, it is the local cathode at the halo edge which is of interest because it principally determines the rate of cathodic failure measured in the body of experimental work presented here.

Group I cations will therefore be able to carry ionic charge into a zone of elevated $\mathrm{pH}$, but in the case of $\mathrm{Mg}^{2+}$ precipitation of solid $\mathrm{Mg}(\mathrm{OH})_{2}$ will occur at a region where local concentrations of $\mathrm{Mg}^{2+}$ and $\mathrm{OH}^{-}$are sufficiently high that the solubility product of $\mathrm{Mg}$ $(\mathrm{OH})_{2}$ is exceeded $\left(\mathrm{K}_{\mathrm{sp}}=3 \times 10^{-11} \mathrm{~mol}^{3} \mathrm{dm}^{-9}\right) .{ }^{20}$ Consequently, there is no scope for cathodic disbondment according to the proposed mechanism represented schematically in Fig. 8 and underfilm corrosion will be dominated by filiform like attack, according to an anodic disbondment mechanism discussed in detail elsewhere. ${ }^{7}$ The same will be true when $\mathrm{HCl}$ is employed to initiate underfilm corrosion as any $\mathrm{H}^{+}$ions will become neutralised during when migrating into a zone of elevated $\mathrm{pH}$. In addition, hydroxide ions produced by cathodic HER accompanying $\mathrm{Mg}$ dissolution within the defect region will also tend progressively raise underfilm $\mathrm{pH}$. The fact that no halo is observed when $\mathrm{HCl}$ is used, and that the resulting underfilm corrosion is exclusively filiform-like, suggests that the neutralisation of the initial low pH by the hydroxide product of cathodic HER is very rapid and there is insufficient proton concentration to cause any initiation of cathodic disbondment.

The close agreement of the characteristics of $E_{c o r r}$ versus distance profiles with previously published results obtained for model PVB coatings applied to both zinc $^{16,18}$ and iron, ${ }^{15,21}$ coupled with the findings of elemental mapping of the post corrosion surface (Fig. 5), would tend to confirm the occurrence of a cathodic disbondment mechanism as illustrated schematically in Fig. 8. However, there are also some notable differences in observed behaviour between PVB-coated E717 and these previous investigations involving other metallic surfaces. The first concerns the type of disbondment kinetics observed, where delamination distance characteristically varies as a function of the square root of time, indicating migration control due to a rate determining step involving transport of cations from the defect region to the cathodic front. ${ }^{19}$ The linear relationship of distance with time typified in Figs. 3 and 6 suggests that a different process controls the propagation of the delamination cell in the case of organic coated E717. Under circumstances where a similar deviation from parabolic kinetics has been observed for a PVB coated metal surface, the change has been ascribed to a situation where cathodic oxygen reduction rather than cation migration has become the rate limiting step. ${ }^{18,22}$ This also seems consistent with observations of increased cathodic delamination resistance of zinc surfaces in the presence of alloyed $\mathrm{Mg}$, where the insulating nature of the surface magnesium (hydr)oxide film at the metalcoating interface serves as a barrier to electron transfer during underfilm cathodic oxygen reduction. ${ }^{22-24}$ In addition, the insensitivity of delaminated area propagation to the type of group I cation present, observed in Fig. 8, seems also to be in accordance with the change in the rate limiting step. A migration controlled mechanism would have revealed a significant dependence on cation type, where the mobility of cations differs markedly between $\mathrm{Li}^{+}$through to $\mathrm{Cs}^{+}$. The small size and consequent high charge density of $\mathrm{Li}^{+}$ions dissolved in water produces a large solvation shell, rendering this cation the least mobile. However, Fig. 8 shows that the delaminated area rate remains the same for both the least $\left(\mathrm{Li}^{+}\right.$, plot $\left.\mathrm{i}\right)$ and most mobile $\left(\mathrm{Cs}^{+}\right.$, plot iv) cation types.

A question arises as to the role of oxygen reduction in the cathodic disbondment phenomenon observed for group I chloride initiated atmospheric corrosion of PVB-coated E717. Recent publications have proposed that oxygen reduction (Eq. 2) may make a significant contribution to the total cathodic current during the corrosion of $\mathrm{Mg}$ alloy surfaces in the absence of external polarisation both under immersion ${ }^{25}$ and atmospheric corrosion ${ }^{26}$ conditions. In contrast, others have reported that the partial cathodic current due to oxygen reduction on a polarised pure $\mathrm{Mg}$ electrode under immersion remains insignificant compared to that due to the reduction of water. ${ }^{27}$ The measurable difference in delamination distance vs time slopes measured in the presence and absence of oxygen shown in Fig. 6 tends to suggest that reaction (2) may contribute to the cathodic current at the site of coating disbondment. This notion is reinforced by the obvious visual difference between delaminated specimens held in humid air when compared with nitrogen. Nevertheless, the fact that an obvious delaminated halo develops in the absence of oxygen, at a significant rate implies that oxygen reduction provides a relatively minor contribution to the overall cathodic disbondment process. A final question to be addressed refers to the exact nature of the physical and/or chemical processes which are directly responsible for the loss of organic coating adhesion from the Mg alloy surface. In the case of Fe, loss of adhesion by the destruction of polymer-metal bonds by hydrogen peroxide and other reactive intermediates in cathodic oxygen reduction is proposed, ${ }^{13,14}$ while the dissolution of an amphoteric zinc oxide film at the metal-coating interface can occur in the case of organic coated $\mathrm{Zn} .{ }^{16,17}$ However, neither is possible in the case of $\mathrm{Mg}$, where cathodic disbondment persists in the absence of oxygen and where the predominant surface oxide is nonamphoteric. It therefore seems plausible to suggest that the principal mode of de-adhesion consists of interfacial base 
catalysed polymer hydrolysis degradation, although it may also be possible that hydrogen gas bubbles, generated at the disbondment front may also play a role by mechanically forcing the coating from the $\mathrm{Mg}$ alloy surface. Further work is underway to clarify the mode(s) by which de-adhesion occurs.

In conclusion, the nature of chloride-induced underfilm corrosion occurring on PVB-coated E717 Mg alloy specimens was studied using a combination of in-situ time lapse photography and scanning Kelvin probe analysis. Corrosion was initiated by applying various chloride based salts to a penetrative scribed coating defect and samples were then held in air at 93\% RH for periods of up to 3 days. All specimens showed evidence of filiform-like corrosion, characterised by the underfilm evolution of a network of dark tracks which lengthen with time. However, significant differences in corrosion behaviour were observed between specimens initiated using group I chlorides compared with those where either $\mathrm{HCl}$ or $\mathrm{MgCl}_{2}$ was used. In the case of the former, propagation of dark filiform tracks was preceded by the rapid development of a halo of apparently disbonded coating surrounding the defect region, which expanded radially with time. When initiation was carried out using either $\mathrm{HCl}$ or $\mathrm{MgCl}_{2}$, no evidence of a preceding halo was observed. Post corrosion surface analysis using imaging SIMS showed that the region affected by the halo was abundant in the initiating cation, but that chloride ions were not present. Further experiments carried out in a humidified nitrogen atmosphere showed that a halo was observed even in the absence of oxygen. Taken together, the findings suggest that a hitherto unreported cathodic disbondment mechanism is operational on certain model organic coated Mg alloys, where anodic activity at a penetrative defect is coupled with a underfilm reduction reaction predominantly involving cathodic hydrogen evolution. This phenomenon is only observed when group I cations are available which can sustain ionic current within a region of high alkalinity. However, although the observations made above confirm that a cathodic disbondment mechanism is in operation, there are differences with behaviour reported on other metals such as iron and zinc. The linear relationship of disbondment front distance with respect to time suggests that the rate determining step may not involve transport of cations from the anode to the underfilm cathode, typically characterised by parabolic kinetics. Rather the observation suggests that electron transfer at the principal underfilm cathode may govern the overall rate. This appears to be consistent with the observed independence of delamination rate on the type of group I chloride salt used to initiate corrosion.

\section{METHODS}

\section{Materials and experimental details}

Polyvinylbutyral-co-vinyl alcohol-co-vinyl acetate (PVB), molecular weight 70,000-100,000 was obtained from the Aldrich Chemical Company. All other chemicals were obtained from Sigma-Aldrich Ltd in analytical grade purity. E717 (ZEK100) sheet of $1.5 \mathrm{~mm}$ thickness was provided by Chemetall $\mathrm{GmbH}$ (nominal composition by weight: $1.25 \% \mathrm{Zn}, 0.5 \% \mathrm{Zr}$, $0.22 \% \mathrm{Nd}, 0.008 \% \mathrm{Cu}, 0.004 \% \mathrm{Fe}, 0.3 \%$ others, balance $\mathrm{Mg}, \mathrm{F}$ temper), which was cut into $50 \times 50 \mathrm{~mm}$ coupons. Specimens of AZ31 were machined from as-cast ingots supplied by Magnesium Elektron Ltd (AZ31: composition $3.1 \% \mathrm{Al}, 0.7 \% \mathrm{Zn}, 0.24 \% \mathrm{Mn}$; AZ91: $8.9 \% \mathrm{Al}, 0.8 \% \mathrm{Zn}$, and $0.26 \% \mathrm{Mn}$ (all wt $\%$ ) with balance $\mathrm{Mg}$ ), while pure $\mathrm{Mg}$ specimens ( $<80 \mathrm{ppm}$ Fe) were prepared, as described previously. ${ }^{28}$ These were subsequently abrasively using $1200 \mathrm{SiC}$ paper, followed by an aqueous slurry of $5 \mu \mathrm{m}$ polishing alumina and then cleaned with detergent solution and finally rinsed with distilled water followed by ethanol. Model PVB coatings were bar cast over one face of the coupons using a $16 \% \mathrm{w} / \mathrm{w}$ ethanolic PVB solution to produce an air-dried coating thickness of $20 \pm 5 \mu \mathrm{m}$, as determined using a micrometre screw gauge. A $10 \mathrm{~mm}$ long linear penetrative defect, running perpendicular to the substrate rolling direction, was created in the centre of each coated coupon using a scalpel blade. When required, underfilm corrosion was initiated using $1 \mu \mathrm{l}$ of $1 \mathrm{~mol} \mathrm{dm}^{-3}$ aqueous solutions of either $\mathrm{HCl}, \mathrm{NaCl}, \mathrm{LiCl}, \mathrm{KCl}, \mathrm{CsCl}$ or $0.5 \mathrm{M}$ $\mathrm{MgCl}_{2}$ distributed evenly along the defect using a microlitre syringe (Hamilton Ltd).

Potentiometric measurements under atmospheric corrosion conditions were carried out using SKP instrumentation described in detail elsewhere. ${ }^{29}$ The SKP reference probe consisted of a $125 \mu \mathrm{m}$ diameter gold wire vibrated normal to the sample surface at $280 \mathrm{~Hz}$, with a $30 \mu \mathrm{m}$ peakto-peak amplitude, and mid-amplitude probe-sample distance of $100 \mu \mathrm{m}$ and was calibrated prior to its use using a previously published procedure. ${ }^{16}$ Following initiation of underfilm corrosion as above, PVB coated E717 samples were held initially in room air (ca. $20^{\circ} \mathrm{C}$ and $50 \% \mathrm{RH}$ ) for $10 \mathrm{~min}$ and then transferred to the SKP environment chamber, which was maintained at $20^{\circ} \mathrm{C}$ and $93 \% \mathrm{RH}$ in isopiestic equilibrium with a saturated aqueous $\mathrm{Na}_{2} \mathrm{SO}_{4} \cdot 10 \mathrm{H}_{2} \mathrm{O}$ reference solution. SKP scans were initiated immediately and repeated every ca. $6 \mathrm{~h}$ for up to $72 \mathrm{~h}$. Each scan comprised a rectangular grid of $120 \times 140$ data points over a $6 \mathrm{~mm} \times 7 \mathrm{~mm}$ area situated to one side of the coating defect. At the end of each SKP atmospheric corrosion experiment, samples were photographed in room air.

Time-lapse photographic investigations of atmospheric-corrosion induced PVB coating failure of PVB coated Mg alloy surfaces was carried out by holding specimens in a container which allowed humidified air or nitrogen to be introduced. The vessel comprised an optically flat glass window, allowing images of the corroding surface to be recorded in-situ along with a reservoir of saturated $\mathrm{Na}_{2} \mathrm{SO}_{4} \cdot 10 \mathrm{H}_{2} \mathrm{O}(\mathrm{aq})$ to maintain constant R.H. An arrangement of three Dreschel bottles containing saturated aqueous $\mathrm{Na}_{2} \mathrm{SO}_{4} \cdot 10 \mathrm{H}_{2} \mathrm{O}$ solution, connected in series, was used to produce a humidified air or $\mathrm{N}_{2}$ gas flow. Elemental analysis of post-corrosion $\mathrm{Mg}$ alloy surfaces was carried out after carefully stripping the PVB coating, (immediately after specimen removal from the humidified container) using a MiniSIMS ToF instrument supplied by SAI Ltd.

\section{DATA AVAILABILTY}

The datasets generated and/or analysed during the current study are available from the corresponding author at reasonable request.

Received: 15 July 2019; Accepted: 13 November 2019; Published online: 04 December 2019

\section{REFERENCES}

1. Gray, J. E. \& Luan, B. Protective coatings on magnesium and its alloys - a critical review. J. Alloy. Compd. 336, 88-113 (2002).

2. Chen, X. B., Birbilis, N. \& Abbott, T. B. Review of corrosion-resistant conversion coatings for magnesium and its alloys. Corrosion 67, 035005-1 (2011).

3. Hu, R. G., Zhang, S., Bu, J. F., Lin, C. J. \& Song, G. L. Recent progress in corrosion protection of magnesium alloys by organic coatings. Prog. Org. Coat. 73, 129-141 (2012).

4. Song, S., Song, G. L., Shen, W. \& Liu, M. Corrosion and electrochemical evaluation of coated magnesium alloys. Corrosion 68, 015005-1 (2012).

5. Brady, M. P. et al. Advanced characterization study of commercial conversion and electrocoating structures on magnesium alloys AZ31B and ZE10A. Surf. Coat. Technol. 294, 164-176 (2016).

6. Liu, B., Wei, Y., Chen, W., Hou, L. \& Guo, C. Blistering failure analysis of organic coatings on AZ91D Mg-alloy components. Eng. Fail. Anal. 42, 231-239 (2014).

7. Williams, G. \& Grace, R. Chloride-induced filiform corrosion of organic-coated magnesium. Electrochim. Acta 56, 1894-1903 (2011).

8. Niu, X. P., Skszek, T., Fabischek, M. \& Zak, A. Low temperature warm forming of magnesium ZEK 100 sheets for automotive applications. Mater. Sci. Forum 431, 783-786 (2014).

9. Brady, M. P., Joost, W. J. \& Warren, C. D. Insights from a recent meeting: current status and future directions in magnesium corrosion research. Corrosion 73, 452-462 (2017).

10. Brady, M. P. et al. Film breakdown and nano-porous $\mathrm{Mg}(\mathrm{OH})_{2}$ formation from corrosion of magnesium alloys in salt solutions. J. Electrochem. Soc. 162, C140-C149 (2015).

11. Williams, G. \& McMurray, H. N. The kinetics of chloride-induced filiform corrosion on aluminum alloy AA2024-T3. J. Electrochem. Soc. 150, B380-B388 (2003).

12. Stratmann, M., Streckel, H. \& Feser, R. A new technique able to measure directly the delamination of organic polymer films. Corros. Sci. 32, 467-470 (1991).

13. Stratmann, M., Feser, R. \& Leng, A. Corrosion protection by organic films. Electrochim. Acta 39, 1207-1214 (1994). 
14. Leng, A., Streckel, H. \& Stratmann, M. The delamination of polymeric coatings from steel. Part 1: Calibration of the Kelvinprobe and basic delamination mechanism. Corros. Sci. 41, 547-578 (1999).

15. Williams, G. \& McMurray, H. N. The mechanism of group (I) chloride initiated filiform corrosion on iron. Electrochem. Commun. 5, 871-877 (2003).

16. Williams, G. \& McMurray, H. N. Chromate inhibition of corrosion-driven organic coating delamination studied using a scanning Kelvin probe technique. J. Electrochem. Soc. 148, B377-B385 (2001).

17. Furbeth, W. \& Stratmann, M. The delamination of polymeric coatings from electrogalvanised steel - a mechanistic approach: Part 1: delamination from a defect with intact zinc layer. Corros. Sci. 43, 207-227 (2001)

18. Williams, G., Holness, R. J., Worsley, D. A. \& McMurray, H. N. Inhibition of corrosiondriven organic coating delamination on zinc by polyaniline. Electrochem. Commun. 6, 549-555 (2004).

19. Leng, A., Streckel, H. \& Stratmann, M. The delamination of polymeric coatings from steel. Part 2: First stage of delamination, effect of type and concentration of cations on delamination, chemical analysis of the interface. Corros. Sci. 41, 579-597 (1998)

20. Lide, D. R. CRC Handbook of Chemistry and Physics, 78th edn. (CRC Press Inc., Boca Raton, USA, 1997).

21. Williams, G. \& McMurray, H. N. Inhibition of corrosion driven delamination on iron by smart-release bentonite cation-exchange pigments studied using a scanning Kelvin probe technique. Prog. Org. Coat. 102, 18-28 (2017).

22. Davies, J. L., Glover, C. F., Van de Langkruis, J., Zoestbergen, E. \& Williams, G. The effect of Mg concentration on the resistance of PVD Zn-Mg coatings to corrosion driven organic coating delamination. Corros. Sci. 100, 607-618 (2015).

23. Hausbrand, R., Stratmann, M. \& Rohwerder, M. Delamination resistant zinc alloys: simple concept and results on the system zinc-magnesium. Steel Res. Intenational 74, 453-458 (2003).

24. Hausbrand, R., Stratmann, M. \& Rohwerder, M. Corrosion of zinc-magnesium coatings: mechanism of paint delamination. Corros. Sci. 51, 2107-2114 (2009).

25. Silva, E. L., Lamaka, S. V., Mei, D. \& Zheludkevich, M. L. The reduction of dissolved oxygen during magnesium corrosion. ChemistryOpen 7, 664-688 (2018).

26. Stebl, M. \& Virtanen, S. Real-time monitoring of atmospheric magnesium alloy corrosion. J. Electrochem. Soc. 166, C3001-C3009 (2019).

27. Han, J. \& Ogle, K. Dealloying of $M g Z n_{2}$ intermetallic in slightly alkaline chloride electrolyte and its significance in corrosion resistance. J. Electrochem. Soc. 164, C952-C961 (2017)

28. Michailidou, E., McMurray, H. N. \& Williams, G. Quantifying the role of transition metal electrodeposition in the cathodic activation of corroding magnesium. J. Electrochem. Soc. 165, C195-C205 (2018).

29. Williams, G., McMurray, H. N. \& Worsley, D. A. Latent fingerprint detection using a scanning Kelvin microprobe. J. Forensic Sci. 46, 1085-1092 (2001).

\section{ACKNOWLEDGEMENTS}

The support of BASF's Coatings division and Swansea University's EPSRC-funded Centre for Doctoral Training in advanced functional coatings (COATED ${ }^{2}$ ), administered through the Materials and Manufacturing Academy, is acknowledged.

\section{AUTHOR CONTRIBUTIONS}

C.K. prepared the specimens and carried out the experimental work. G.W. was the principal author of the paper, and along with C.K. prepared the figures. HNM and PK contributed to the design of the research programme and analysis of the results. All authors revised and corrected the manuscript.

\section{COMPETING INTERESTS}

The authors declare no competing interests.

\section{ADDITIONAL INFORMATION}

Correspondence and requests for materials should be addressed to G.W.

Reprints and permission information is available at http://www.nature.com/ reprints

Publisher's note Springer Nature remains neutral with regard to jurisdictional claims in published maps and institutional affiliations.

(i) Open Access This article is licensed under a Creative Commons adaptation, distribution and reproduction in any medium or format, as long as you give appropriate credit to the original author(s) and the source, provide a link to the Creative Commons license, and indicate if changes were made. The images or other third party material in this article are included in the article's Creative Commons license, unless indicated otherwise in a credit line to the material. If material is not included in the article's Creative Commons license and your intended use is not permitted by statutory regulation or exceeds the permitted use, you will need to obtain permission directly from the copyright holder. To view a copy of this license, visit http://creativecommons. org/licenses/by/4.0/.

(c) The Author(s) 2019 